\title{
ON POSSIBLE RELATION OF EARTHQUAKES WITH THE SIGN CHANGE OF THE INTERPLANETARY MAGNETIC FIELD RADIAL COMPONENT
}

\author{
O.D. Zotov \\ Borok Geophysical Observatory of IPhE RAS, \\ Borok,Russia,ozotov@inbox.ru \\ Schmidt Institute of Physics of the Earth RAS, \\ Moscow, Russia, ozotov@inbox.ru
}

\author{
A.V. Guglielmi \\ Schmidt Institute of Physics of the Earth RAS, \\ Moscow, Russia,guglielmi@mail.ru \\ A.S. Silina \\ Schmidt Institute of Physics of the Earth RAS, \\ Moscow, Russia,silina@ifz.ru
}

\begin{abstract}
This work is devoted to an experimental study of the possible relationship between earthquakes and interplanetary magnetic field (IMF) variations. For the analysis, we use world and regional catalogs of earthquakes and a catalog containing data on the IMF sector structure for several decades. The main methodological technique consists in a comparative analysis of the occurrence rate of earthquakes on the days when Earth crosses the boundary between IMF sectors with the days when Earth is inside the sector. The sign of the IMF radial component is utilized as an indicator of the events on which the oscillation mode of Earth's magnetosphere depends. The sign reversal signals the probable crossing of the boundary between the IMF sectors by Earth, or, in other words, the crossing of the heliospheric current sheet by Earth. The hypothesis about the rela-
\end{abstract}

tionship between IMF variations and seismic activity is that IMF fluctuations, penetrating into the magnetosphere, excite ULF electromagnetic oscillations in the magnetosphere, which, in principle, can affect the physical processes in upcoming earthquake sources. We have found a weak, but statistically significant relationship between IMF variations and seismic activity. We also consider other IMF parameters that control ultralow-frequency oscillations of the geomagnetic field.

Keywords: heliosphere, sector structure, magnetosphere, lithosphere, earthquakes, ultra-low-frequency oscillations, magnetoplasticity.

\section{INTRODUCTION}

Seismomagnetic phenomena can be conveniently divided into two categories: phenomena accompanying seismic events as their consequences; phenomena triggering the events (stimulating or suppressing them). The former category includes the phenomena in which mechanical processes in the earth's crust can, with some degree of certainty, be regarded as the cause of geomagnetic variations. An example is quasi-periodic magnetic field variations accompanying propagation of elastic waves at a distance away from an earthquake source, as well as magnetic pulses occurring at the source when the main rupture of rock continuity is formed (see the review [Guglielmi, 2007] and references therein). This category also includes observations of magnetic precursors of earthquakes, generated in the earth's crust at the stage of the main rupture formation. The references below do not reflect the wealth of literature on magnetic earthquake precursors [Kalashnikov, 1954; Moore, 1964; Fraser-Smith et al., 1990; Hayakawa, 2001; Hattori, 2004; Dovbnya, 2009; Sobisevich et al., 2010; Masci, 2011; Guglielmi, Zotov, 2012a; Schekotov et al,. 2012; Zotov et al., 2013].

In this paper, we focus on the seismomagnetic phenomena that fall into the latter category. This category includes phenomena in which the effect of alternating magnetic field on rocks would, presumably, be a direct or indirect cause of earthquakes. Many independent studies argue for the presence of such phenomena. The papers [Zakrzhevskaya, Sobolev, 2002, 2004; Duma,
Ruzhin, 2003; Balasis et al., 2011; Adushkin et al., 2012; Zotov et al., 2013; Guglielmi et al., 2015a, Tarasov, 2017] describe a weak, but statistically significant correlation between seismic activity and natural geomagnetic disturbances, which occur during the interaction between Earth's magnetosphere and the solar wind. The papers [Velikhov, Volkov, 1981; Tarasov, 1997; Tarasov et al., 2000, 2001; Savin, Smagin, 2004] observe a correlation between seismic activity and artificial field pulses, produced by powerful MHD generators.

The impetus for our work was the idea about the role of magnetoplasticity in rock mechanics [Buchachenko 2014, 2019]. It is based on the fundamental magnetochemistry concepts of the nontrivial mechanism behind solid strength modification due to magnetic interaction in electron-spin pairs on the dislocations. Physicists and geophysicists have discussed power and thermal effects of electromagnetic field on rocks in a seismic focus (see, e.g., [Guglielmi, 1992; Fainberg et al., 2004]). According to the estimates, however, neither ponderomotive forces nor heating by eddy currents can provide a convincing explanation for the correlation of seismic activity with natural and artificial magnetic field pulses. The third mechanism behind the electromagnetic field effect on rocks in a seismic focus (it can be called magnetoplastic or magnetochemical), proposed by Buchachenko, opens up new prospects for seismoelectromagnetic studies and stimulates further search for possible manifestations of the alternating magnetic field effect on the earth's solid mantle.

The paradoxical formulation of the problem, as re- 
flected in the title of our article, lies in the fact that the interplanetary magnetic field B (IMF) is not in contact with the earth's solid mantle and hence has no direct effect on seismic activity. Our hypothesis is that IMF fluctuations, penetrating from a foreshock region into the magnetosphere, excite ultra-low frequency (ULF) electromagnetic oscillations in the magnetosphere, which can, in principle, have an effect on physical processes in earthquake sources.

Formulating the problem in such an unusual way, we are guided by the idea that $\mathbf{B}$ vector components and their quite certain combinations play a key role in the formation of geomagnetic activity [Guglielmi et al., 2015b]. The IMF vector in the geocentric solarmagnetospheric coordinate system, used in this article, is shown schematically in Figure 1.

For example, it has long been known that the change of sign of the $B_{z}$ component from positive to negative stimulates sharp intensification of the magnetosphere, the ionosphere and, by and large, the atmosphere, which is manifested in the form of geomagnetic storms, auroral flashes, radio communication failures, excitation of powerful infrasonic waves, etc. [Nishida, 1980]. No less interesting, though not so dramatic changes in geospheres occur when the radial component $B_{x}$ changes sign. It is changes of $B_{x}$ sign that we focus our attention on. Thus formulated, the problem has been previously considered in [Zotov, Lavrov, 2017]. We briefly describe other possible formulations of the problem in order to verify the IMF effect on seismicity in the section «Discussion».

Let us explain our choice of the radial component $B_{x}$ as a driving parameter, on which the state of the geomagnetic field depends. IMF is known to have a sector structure [Parker, 1965]. Crossing the boundary between adjacent sectors, the $B_{x}$ sign is reversed. If $B_{x}<0$, the sector is called positive; if $B_{x}>0$, negative. The IMF sector structure reflects the existence of the so-called heliospheric current sheet (HCS) in interplanetary space, which separates fields of mutually opposite directions. HCS passes through the solar system - from the Sun to the stagnation region on the boundary with the interstellar medium. This permanent structural feature has a folded shape and is located in the vicinity of the ecliptic plane.

Our interest in HCS was generated by two factors. First, the interaction of Earth with HCS leads to a specific variation in magnetospheric ULF oscillations [Guglielmi, Pokhotelov, 1996], which is of concern from the viewpoint of seismomagnetism. Second, the moment when HCS is crossed is convenient to utilize as a reference in the statistical processing of a large amount of numerical information on earthquakes.

\section{INITIAL DATA AND ANALYSIS METHOD}

We call specific days, about which we know the position of Earth in the IMF sector structure and the number of earthquakes with any given magnitude in a preselected region or on Earth as a whole, an event. Information about the IMF sector structure was taken from

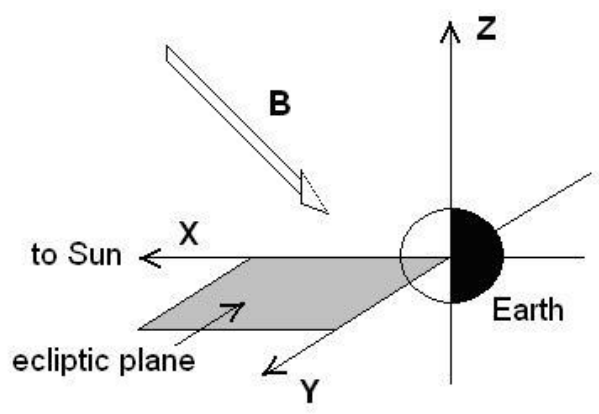

Figure 1. IMF vector in the geocentric solarmagnetospheric coordinate system

the IZMIRAN catalog [http: //www.izmiran.ru/stp/polar/ SSIMF/?ASCII], compiled using Mansurov's method. Initial data includes semidiurnal values of sector sign. Recall that the sector is called positive $(+)$ or negative (-) depending on whether the field is antisunward or sunward. If the IZMIRAN catalog contains ++ or -- , we assume that Earth is in the positive or negative sector; if +- or -+ , we hold that during this event Earth crosses HCS. In the former case, an event is called regular; and in the latter, significant. These names are, of course, conventional, but have a quite clear meaning. Statistics of regular and significant days in the IZMIRAN catalog from 1958 to 2015 is as follows: 15771 regular days $(7351++$ and $8420-$ $-), 5145$ significant days $(2990+-$ and $2155-+)$; 268 days were omitted (IMF sign was not determined).

In such a relatively rough selection of regular and significant events, errors associated both with errors in determining IMF polarity and with erroneous judgment that Earth crossed precisely the heliospheric current sheet are inevitable - in fact the IMF loops frozen in flare-induced solar plasma stream passed Earth.

We decided to adopt this very simplified method for processing large volumes of numerical information before performing a more refined analysis, using satellite data on IMF.

To gain information about seismicity for each event, we have used the following catalogs:

1. Earthquake catalog of the International Seismological Centre (ISC), 1964-2010 [http://www.isc.ac.uk];

2. Catalog of the National Earthquake Information Center of U.S. Geological Survey USGS/NEIC, 19732014 [http://neic.usgs.gov/neis/epic/epic_global.html];

3. Catalog of the Northern California Earthquake Data Center, 1968-2007 [http://www.ncedc.org];

4. Catalog of the Southern California Earthquake Data Center, 1983-2008 [http://www.data.scec.org];

5. Catalog of earthquakes in Greece, 1964-2009 [http://www.gein.noa.gr].

The total number of events we have analyzed is quite large - it varies approximately from 10000 to 15 000 , depending on the catalog. We have divided the events into groups differing in IMF polarity and earthquake magnitude. The main methodological technique consists in a comparative analysis of the occurrence rate of earthquakes in different groups of events. 
Let us emphasize that we did not rule out aftershock sequences from the analysis. We did it for the following reasons. First, aftershocks, from the physical point of view, do not differ fundamentally from main shocks, despite somewhat different causes of their occurrence. Second, aftershock sequences are equally likely to occur both on regular and on significant days. Third, in our study, the characteristic interval of the analysis is 24 hours; the duration of the aftershock sequences is substantially longer, sometimes to 2-3 years. Thus, without excluding aftershock sequences from the analysis, we actually study the relationship between IMF and earthquakes.

\section{ANALYSIS RESULT}

Table 1 presents the result of calculation of the mean occurrence rate of earth shocks derived from the aforementioned earthquake catalogs. We did not select events by earthquake magnitude. This means that Table 1 reflects mainly the occurrence rate of relatively minor earthquake shocks. We can see that the days when the IMF polarity was stable the occurrence rate of earthquakes was much lower than the days when the polarity changed. This consistent trend is observed in four of the five catalogs. The exception is the result of calculation from the catalog of the Southern California Earthquake Data Center: in this case, regular and significant events differ little in the average number of earthquakes per day.

To assess the statistical significance of differences in the numbers listed in the two right-hand columns of Table 1, we have built five pairs of event distributions according to the occurrence rate of earthquakes. The empirical distributions appeared to differ greatly from normal distributions. This is associated with heterogene- ity of each catalog, which is caused by the incremental improvement of the earthquake recording technique and instrumental base, expansion of the network of seismic stations, etc. Therefore, instead of the standard criteria of estimated mean, to compare the distributions we applied the non-parametric Kolmogorov-Smirnov criterion [Smirnov, Dunin-Borkovsky, 1965].

Figure 2 gives an example of such an analysis from the data collected in the catalog of the Northern California Earthquake Data Center. Figure 2, $a$ illustrates distributions of regular (black curve) and significant (gray curve) events by the occurrence rate of earthquakes. Difference between the distributions is statistically significant at the level of $p<0.01$. To verify this, we have violated the separation of events into regular and significant and have performed two control tests. Figure 2, $b$ shows distributions of events by the occurrence rate of earthquakes with -- and -+ (black curve) and with ++ and +- (gray curve). Figure 2, $c$ depicts distributions of regular even (black curve) and odd (gray curve) events (i.e. corresponding to odd and even days of the month). The distributions shown in Figure 2, $b$ and $c$ are statistically identical.

The result of the analysis from the earthquake cata$\log$ data suggests that the difference in the occurrence rate of earthquakes is statistically significant at $p<0.01$ in rows $1,2,3$, and 5 of Table 1 . As for row 4 (South California), the difference in the occurrence rate is statistically insignificant $(p=0.4)$.

To check the stability of this trend, we have divided the catalogs according to three features. First, all the events analyzed were subdivided into four groups according to combination of IMF polarity signs.

Occurrence rate of earthquakes

\begin{tabular}{|c|l|r|r|r|}
\hline \multirow{2}{*}{ No } & \multirow{2}{*}{ Catalog } & \multirow{2}{*}{$\begin{array}{c}\text { Number of } \\
\text { earthquakes }\end{array}$} & \multicolumn{2}{|c|}{ Mean occurrence rate of earthquakes, day } \\
\cline { 4 - 5 } & & & Regular events & Significant events \\
\hline 1 & ISC & 1489169 & 84.51 & 99.63 \\
\hline 2 & USGS & 716405 & 44.26 & 55.78 \\
\hline 3 & North California & 631116 & 40.73 & 50.82 \\
\hline 4 & South California & 405428 & 44.17 & 61.99 \\
\hline 5 & Greece & 88165 & 4.66 & 6.85 \\
\hline
\end{tabular}

Table 1

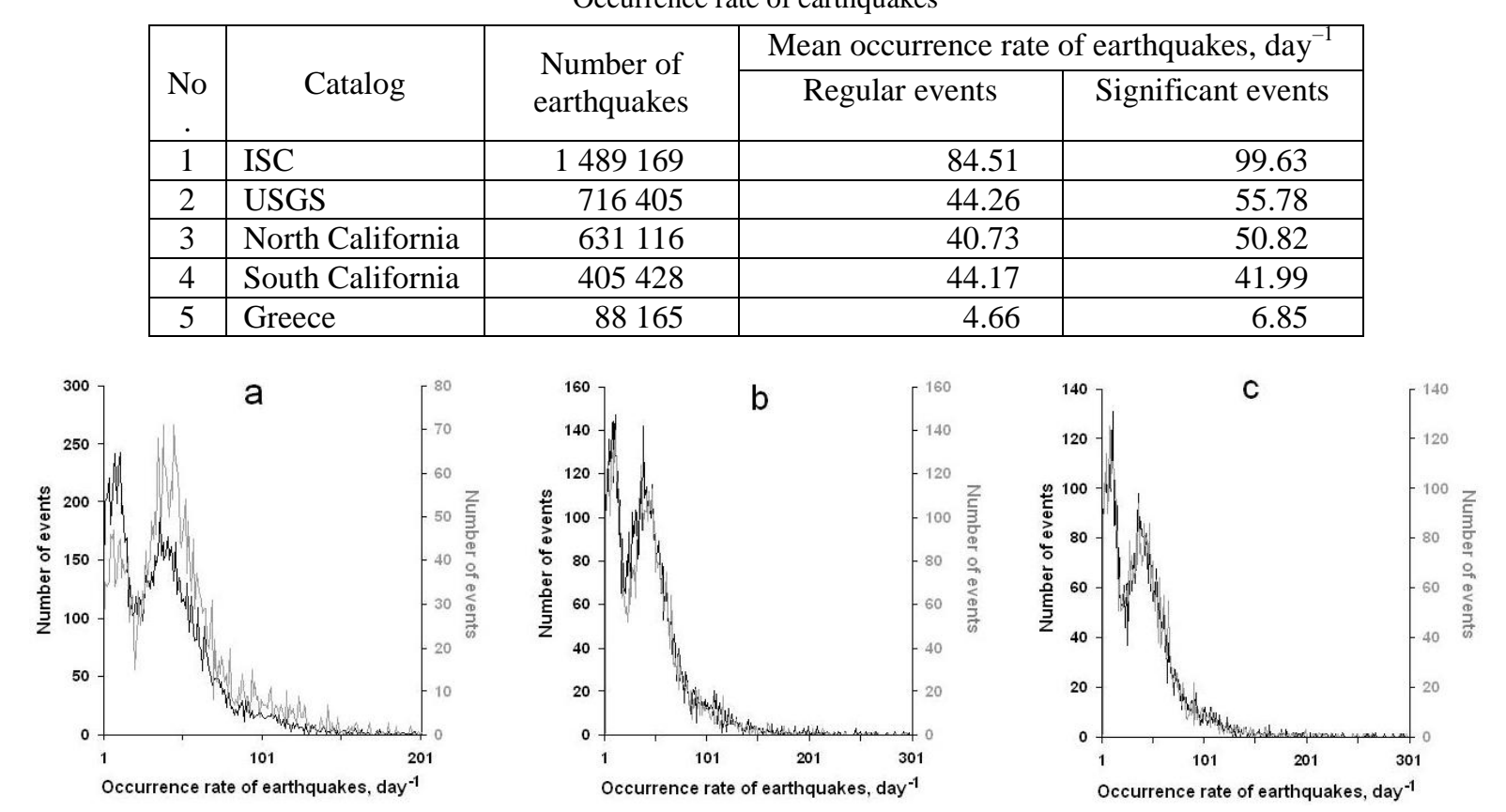

Figure 2. Distribution of regular (black curve) and significant (gray curve) events according to the occurrence rate of earthquakes $(a)$; results of control tests (see the text) $(b, c)$ 
The trend continued for the global catalogs ISC and USGS, as well as for regional catalogs of North California and Greece. As an example, Figure 3 shows distribution of the occurrence rate of earthquakes according to North California catalog data. At the same time, data from the regional catalog of South California still does not show a significant dependence of seismic activity on combination of IMF polarity signs. We could not figure out the reason for this difference.

Then, using data from two global catalogs, we analyzed the dependence of seismicity on IMF polarity separately for the Northern and Southern hemispheres. The result obtained from ISC catalog data is shown in Figure 4. A similar result was received from USGS catalog data.

Figure 5 shows how the trend we observe depends on earthquake magnitude $M$. The regular and significant events were further subdivided into three groups differing in magnitude range. We can see that the trend continues for minor $(M<4.5,23 \%$ difference between means) and moderately strong earthquakes ( $4.5 \square M<6.0$, $12 \%$ difference between means), whereas for severe earthquakes ( $M \square 6.0,0.3 \%$ difference between means), it is not found.

It is known that in the representative part of catalog the distribution of earthquakes by magnitudes obeys the Gutenberg-Richter law $\lg N=a-b M$. Where $N$ is the number of earthquakes, $a$ and $b$ are Gutenberg-Richter

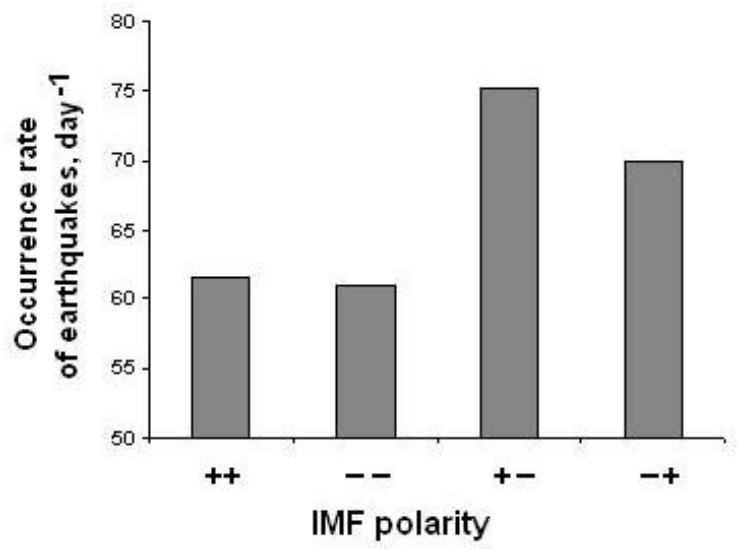

parameters [Kasahara, 1985]. Referring to Figure 5, we can expect that $b$ for significant events will be slightly higher than for regular events.

Indeed, it is the case in the analysis of four of the five catalogs we have studied (rows 2-5), as is evident from the comparison between the fifth and sixth columns in Table 2 .

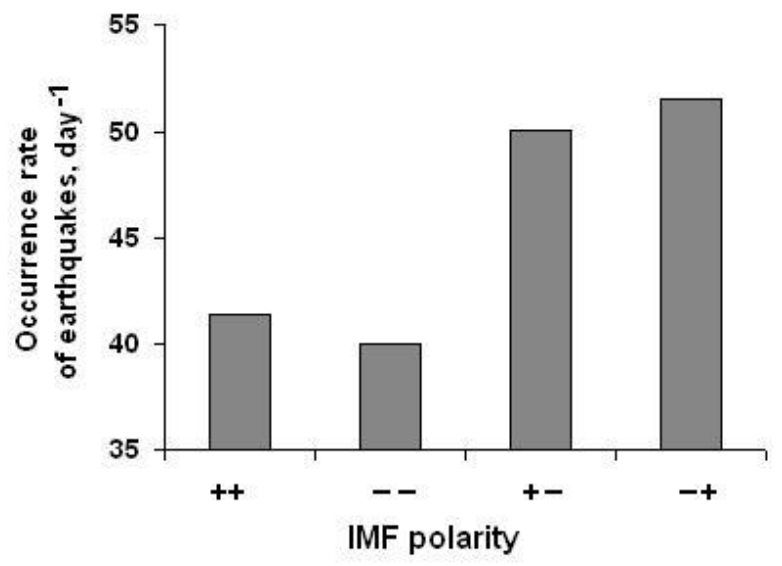

Figure 3. Occurrence rate of earthquakes in North California as function of IMF polarity

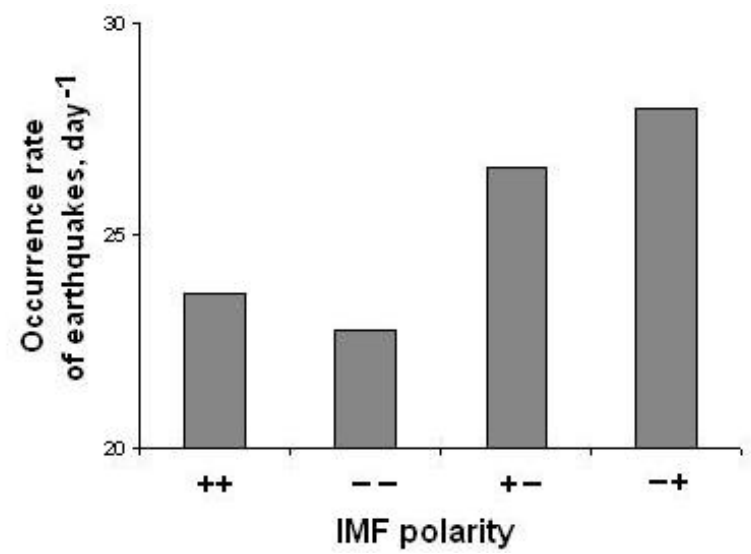

Figure 4. Occurrence rate of earthquakes in the Northern and Southern hemispheres (left and right panels respectively) as function of IMF polarity from ISC catalog data
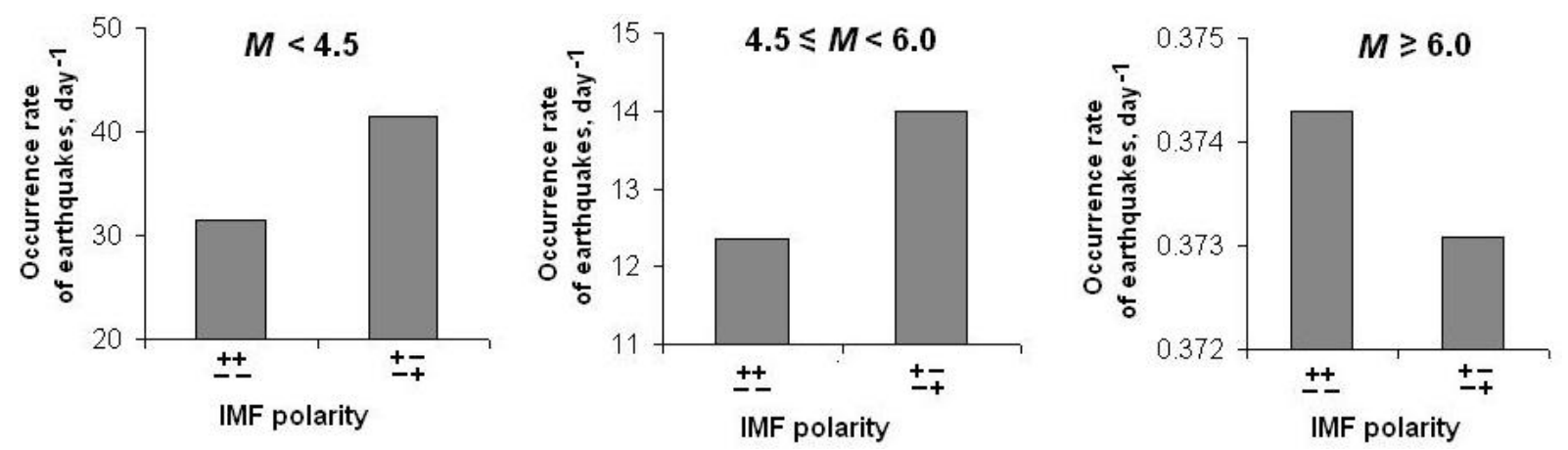

Figure 5. Occurrence rate of earthquakes for regular and significant events for three different ranges of earthquake magnitudes from USGS catalog data

Table 2 
Gutenberg-Richter parameter $b$ for representative parts of catalogs

\begin{tabular}{|c|l|c|c|c|c|}
\hline \multirow{2}{*}{ No. } & \multirow{2}{*}{ Catalog } & \multirow{2}{*}{$\begin{array}{c}\text { Number of } \\
\text { earthquakes } N\end{array}$} & $M$ & Regular events & Significant events \\
\cline { 5 - 6 } & & 54231 & $5.0-7.5$ & 1.16 & 1.06 \\
\hline 2 & USC & 65947 & $5.0-7.5$ & 1.04 & 1.06 \\
\hline 3 & $\begin{array}{l}\text { North } \\
\text { California }\end{array}$ & 40303 & $2.0-5.0$ & 0.94 & 0.98 \\
\hline 4 & $\begin{array}{l}\text { South } \\
\text { California }\end{array}$ & 76848 & $2.0-5.0$ & 1.01 & 1.04 \\
\hline 5 & Greece & 14819 & $3.7-5.3$ & 1.29 & 1.33 \\
\hline
\end{tabular}

The hypothesis that is qualitatively confirmed by Figure 5 and Table 2 consists in the fact that the magnetic field pulses occurring when Earth crosses the boundaries between IMF sectors generally affect relatively minor earthquakes. Nonetheless, the difference between $b$ parameters for significant and regular events in Table 2 is still insignificant. To make the hypothesis more plausible, we applied a non-standard technique: first, we constructed distributions of earthquakes by $M$ from the groups of significant and regular events according to USGS catalog data (Figure 6, $a$ ); second, we worked out the ratio of these distributions (Figure 6,b). The straight line represents a regression line approximating experimental points. It is clearly noticeable that the percent of significant events decreases with increasing magnitude, as our
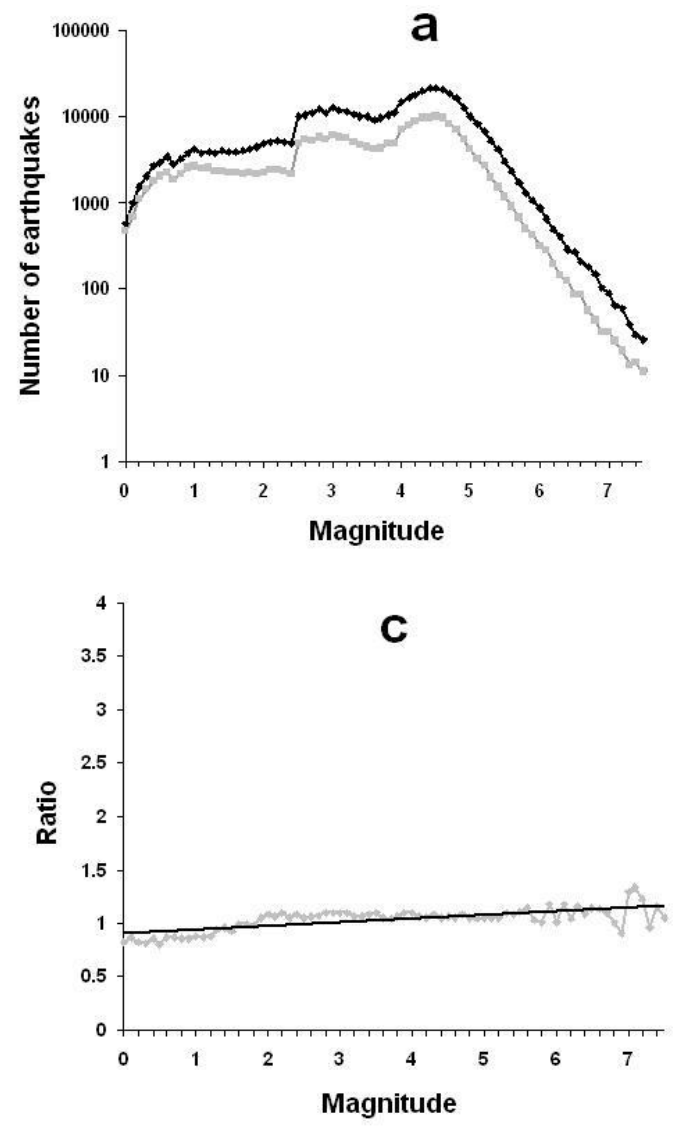

hypothesis predicts.

For further verification, we (as in Figure 2) artificially violated the separation of the events into regular and significant and performed two control tests. Figure 6, $c$ shows the ratio between magnitude distributions of earthquakes with -- and -+ and with ++ and +- . Figure $6, d$ presents the ratio between magnitude distributions of regular odd and even events. We see a complete absence of any dependence on magnitude.

To make the result, shown in Figure 6, and the fact that the effect of the relationship between earthquakes and IMF is also repeated at the regional level more convincing, we present Figure 7, in which is the result of a similar analysis from regional catalog data.
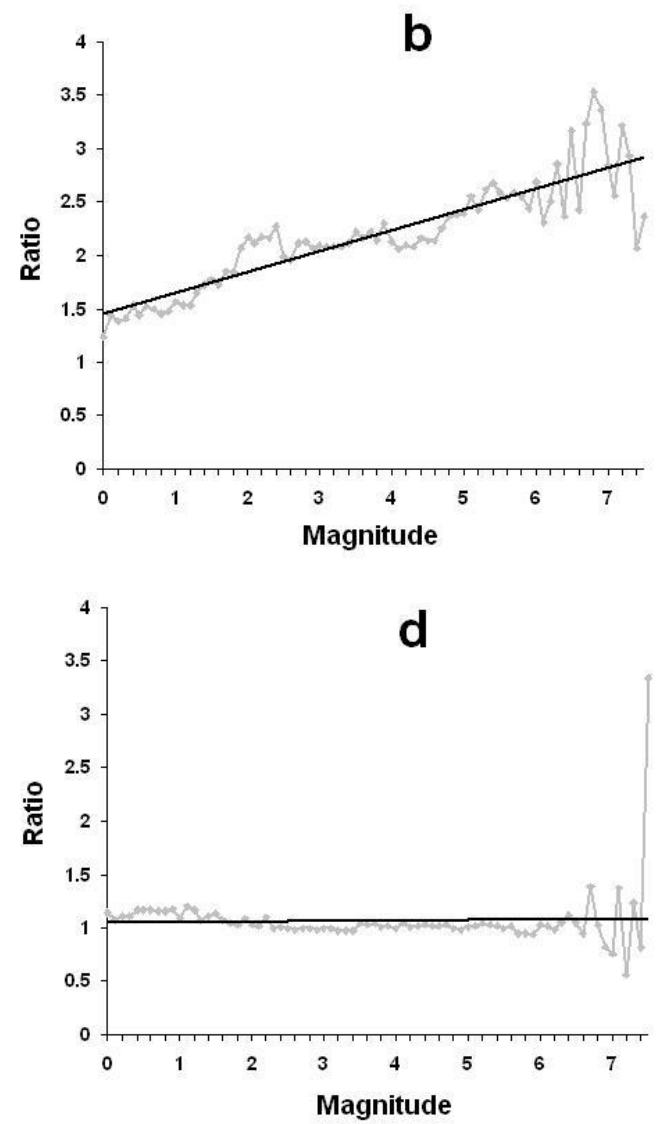

Figure 6. Distribution of earthquakes by magnitude for regular and significant events (black and gray curves respectively) from USGS catalog data $(a)$; ratio of earthquake distributions by magnitudes for regular events to those for significant events $(b)$; results of control tests (see the text) $(c, d)$. Black straight lines are regression lines approximating experimental points 

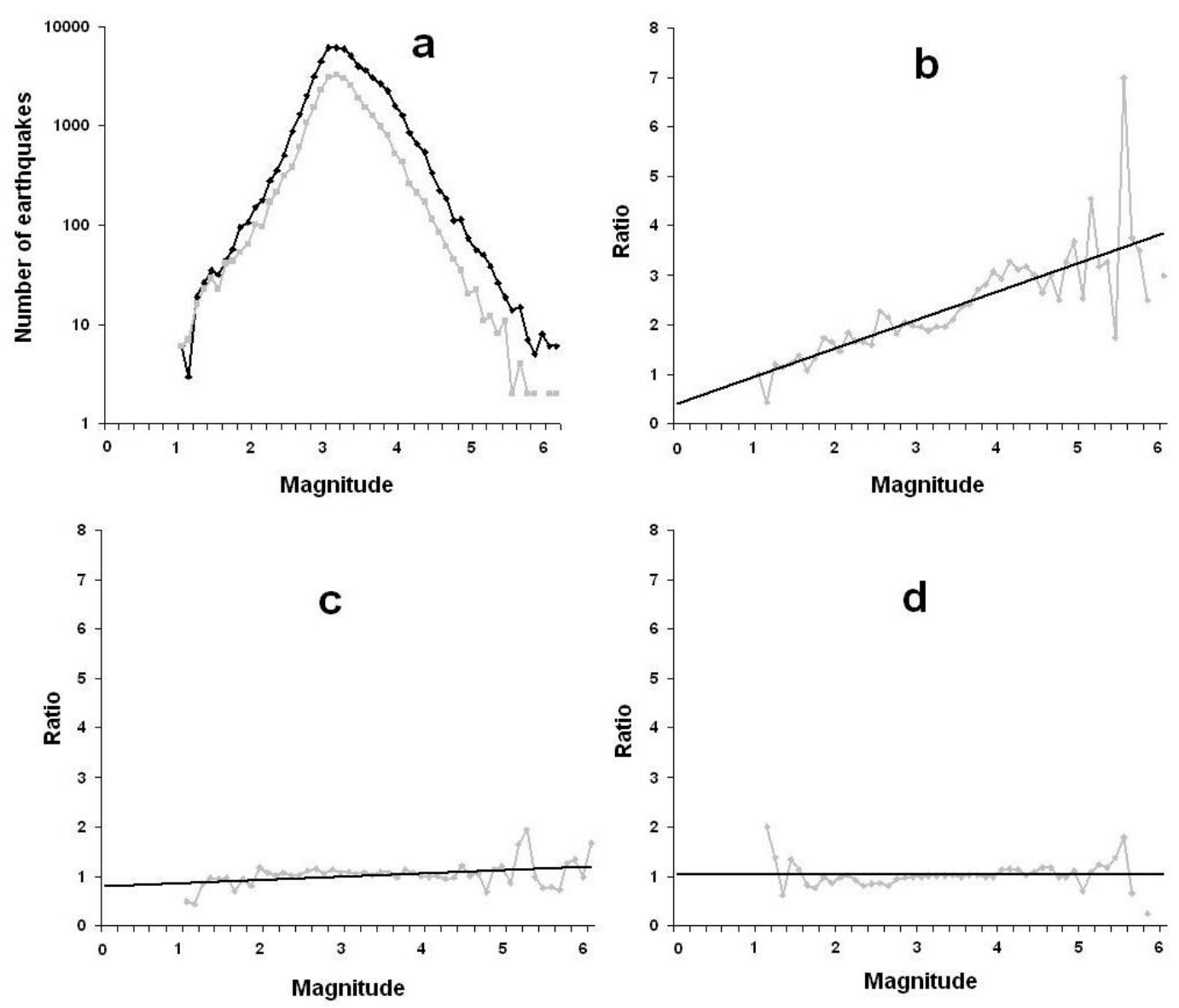

Figure 7. Distribution of earthquakes by magnitude for regular and significant events (black and gray curves respectively) from Greece catalog data $(a)$; ratio of earthquake distributions by magnitudes for regular events to those for significant events $(b)$; results of control tests (see the comment to Figure 6, $c$ and $d)(c, d)$. Black straight lines are regression lines approximating experimental points

\section{DISCUSSION}

In terms of strength, IMF has no particular effect on the dynamics of the magnetosphere, but it plays a key role in transferring momentum and energy from the solar wind into the magnetosphere. In particular, IMF determines the variety of spatio-temporal modes of magnetospheric ULF oscillations [Guglielmi, Pokhotelov, 1996], on which, in turn, physical processes in the lithosphere might depend.

The sign of the field $x$-component $\mathbf{B}$ we have chosen in this study as a dichotomous variable is included in the set of eight control parameters introduced in [Guglielmi et al., 2015b] to explore the response of geospheres to IMF variations. The eight-dimensional space of control parameters is formed from three $\mathbf{B}$ vector components in terms of $\mathbf{B}$ orientation with respect to the Sun-Earth line and the geomagnetic equator and noon meridian planes.

The choice of the $B_{x}$ sign as a control parameter turned out a success. We managed to detect a specific response of the lithosphere that occurred when Earth crossed HCS. It was natural to try to use other elements of the space of control parameters for the statistical analysis of earthquakes. Particularly interesting in the context of the problem addressed seems to be the parameter $\sigma=\operatorname{sign}\left(B_{x} B_{z}\right)$. Using $\sigma$, we have carried out an appropriate pilot analysis of the earthquake catalogs.

The choice of $\sigma$ was motivated by the following considerations. Ahead of the magnetospheric front is the so-called foreshock region. Outside, it is bounded by IMF lines, which are tangent to the front. At $\sigma=-1$, the IMF lines are skewed to the south; and at $\sigma=+1$, to the north. Accordingly, the asymmetry in the foreshock position relative to the equatorial plane changes qualitatively when the sing of $\sigma$ changes. The foreshock region is known to feature powerful electromagnetic fluctuations in a wide frequency range [Russell, Hoppe, 1983]. The hypothesis is that the fluctuations penetrating into the magnetosphere from the foreshock region excite electromagnetic ULF oscillations, which, in principle, can affect physical processes in earthquake sources.

The method of verification involves determining experimentally whether the north-south asymmetry of geomagnetic and seismic activity depending on the sign of $\sigma$ exists or not. In terms of ULF oscillations, our hypothesis has been confirmed [Guglielmi, Potapov, 2017; Guglielmi et al., 2017]. We have not yet, however, found the north-south asymmetry in global seismicity, which would depend on the sign of $\sigma$.

We drew attention to another control parameter, namely $|\mathbf{B}|$ (see [Tobolzhina, 2016]). The mode of excitation of daytime permanent magnetospheric oscillations is known to depend on $|\mathbf{B}|$ [Guglielmi, 2007]. The annual average $|\mathbf{B}|$ deviates little from the typical value of $5 \mathrm{nT}$. It is interesting that the distribution of extreme values of $|\mathbf{B}|$ over years changes significantly. So, from 
2001 to 2005 , the extreme values are in the range $60-80$ nT; and from 2006 to 2010, they differ little from $20 \mathrm{nT}$ (for more information about dynamics of the extreme values of $|\mathbf{B}|$ see [Tobolzhina, 2016]). We have made a preliminary estimate and have found out that in the latter range the number of severe earthquakes (with magnitudes 8 or higher) is 1.5 times larger than in the former. In this regard, it is interesting that according to Buchachenko's idea (which provided the impetus for our study, see Introduction), the reverse should be true for activity of relatively minor earthquakes: in the latter range their number should be much smaller than in the former. We plan to test this prediction in future.

Concluding the discussion, let us delve into such a phenomenon as synchronism of seismic events [Guglielmi, Zotov, 2012b]. Synchronism is manifested in the form of so-called effects of hour marks and weekends. The effect of hour marks occurs at the 24th, 48th, and 96th harmonics; and the effect of weekends, at the 7th subharmonic of circadian rhythm. Both effects indicate a nontrivial effect of the technosphere on the lithosphere. Guglielmi, Zotov [2012b] describe in detail the morphology of the phenomenon and underline the difficulty in its physical interpretation. In light of the above, we can assume that the nature of synchronism may be associated with the global quasiperiodic modulation of electromagnetic fields of industrial origin, which affect rocks in situ.

\section{CONCLUSION}

We seem to have found a small but statistically significant increase in global seismicity when the $\mathbf{B}$ vector $x$ component changes sign, which suggests that Earth crosses the boundary between IMF sectors, or, in other words, the heliospheric current sheet. The result, however, needs, first, to be independently verified and, second, to be interpreted. We hope that it will be interpreted due to the original idea about the role of magnetoplasticity in rock mechanics [Buchachenko, 2014, 2019]. It should be recognized, however, that the actual realization of the idea for the case we considered is currently unknown.

We express our sincere gratitude to A.D. Zavyalov, A.S. Potapov, and A.L. Sobisevich for their interest in the study, numerous discussions, and valuable advice.

The work was financially supported by RFBR (grants Nos. 18-05-00096 and 19-05-00574), and by programs of state tasks of Schmidt Institute of Physics of the Earth RAS.

\section{REFERENCES}

Adushkin V.V., Ryabova S.A., Spivak A.A., Kharlamov V.A Response of the seismic background to geomagnetic variations. Doklady Earth Sci. 2012, vol. 444, no. 1, pp. 642-646. DOI: 10.1134/S1028334X12050157.

Balasis G., Daglis I.A., Anastasiadis A., Papadimitriou C., Mandea M., Eftaxias K. Universality in solar flare, magnetic storm and earthquake dynamics using Tsallis statistical mechanics. Physica A. 2011, vol. A390, pp. 341-346. DOI: 10.1016/ j.physa.2010.09.029.

Buchachenko A.L. Magnetoplasticity and the physics of earthquakes. Can a catastrophe be prevented? PhysicsUspekhi. 2014, vol. 57, no. 1, pp. 92-98. DOI: 10.3367/UFNe. 0184.201401e.0101.
Buchachenko A.L. Microwave stimulation of dislocations and the magnetic control of the earthquake core. PhysicsUspekhi. 2019, vol. 62, no. 1, pp. 46-53. DOI: 10.3367/UFNe. 2018.03.038301.

Dovbnya B.V. On the relation between geomagnetic pulsations and earthquakes. Solar-Terr. Phys. 2009, iss. 13, pp. 82-85. (In Russian).

Duma G., Ruzhin Y. Diurnal changes of earthquake activity and geomagnetic Sq variation. Haz. Earth Sys. Sci. 2003, vol. 3, no. 3/4, pp. 171-177. DOI: 10.5194/nhess-3-171-2003.

Fainberg E.B., Avagimov A.A., Zeigarnik V.A., Vasil'eva T.A. Generation of heat flows in the Earth's interior by global geomagnetic storms. Izvestiya, Physics of the Solid Earth. 2004, vol. 40, no. 4, pp. 315-322.

Fraser-Smith A.C., Bernardi A., McGill P.R., Ladd M.E., Helliwell R.A., Villard O.G., Jr. Low-frequency magnetic field measurements near the epicenter of the Ms 7.1 Loma Prieta earthquake. Geophys. Res. Lett. 1990, vol. 17, pp. 1465-1468. DOI: 10.1029/GL017i009p01465.

Guglielmi A.V. Ponderomotive forces in the crust and magnetosphere of the Earth. Fizika Zemli [Physics of the Solid Earth]. 1992, no. 7, pp. 35-39. (In Russian).

Guglielmi A.V. Ultra-low-frequency electromagnetic waves in the crust and magnetosphere of the Earth. PhysicsUspekhi. 2007, vol. 50, no. 12, pp.1197-1216. DOI: 10.1070/ PU2007v050n12ABEH006413.

Guglielmi A.V., Pokhotelov O.A. Geoelectromagnetic Waves. Bristol and Philadelphia, IOP Publ. Ltd., 1996, 402 p.

Guglielmi A.V., Potapov A.S. Influence of the interplanetary magnetic field on ULF oscillations of the ionospheric resonator. Cosmic Research. 2017, vol. 55, pp. 248-252. DOI: 10.1134/S0010952517030042.

Guglielmi A.V., Zotov O.D. Magnetic perturbations before the strong earthquakes. Izvestiya, Physics of the Solid Earth. 2012a, vol. 48, no. 2, pp. 171-173. DOI: 10.1134/S 1069351312010065.

Guglielmi A.V., Zotov O.D. The phenomenon of synchronism in the magnetosphere-technosphere-lithosphere dynamical system. Izvestiya, Physics of the Solid Earth. 2012b, vol. 48, no. 6, pp. 486-495. DOI: 10.1134/S1069351312050035.

Guglielmi A.V., Lavrov I.P., Sobisevich A.L. Storm sudden commencements and earthquakes. Solar-Terr. Phys.. 2015a, vol. 1, iss. 1, pp. 98-103. DOI: 10.12737/5694. (In Russian).

Guglielmi A.V., Potapov A.S., Dovbnya B.V. The key role of the interplanetary magnetic field in the formation of the oscillation mode of the Earth's magnetosphere. Triggernye effekty $v$ geosistemakh [Trigger effects in geosystems (Moscow, June 16-19, 2015): Proceedings of the 3rd All-Russian workshop-meeting]. Moscow, GEOS Publ., 2015b, pp. 328-334. (In Russian).

Guglielmi A.V., Klain B.I., Potapov A.S. North-south asymmetry of ultra-low-frequency oscillations of Earth's electromagnetic field. Solar-Terr. Phys. 2017, vol. 3, no. 4, pp. 2631. DOI: $10.12737 / \mathrm{stp}-34201703$.

Hattori K. ULF Geomagnetic changes associated with large earthquakes. TAO. 2004, vol. 15, no. 3, pp. 329-360. DOI: 10.3319/TAO.2004.15.3.329(EP).

Hayakawa M. Electromagnetic phenomena associated with earthquakes. IEEJ Trans. Fundam. and Mat. 2001, vol. 121-A, pp. 893-898. DOI: 10.1541/ieejfms.126.211.

Kalashnikov A.G. Possibilities of magnetometric methods in solving the issue of earthquake precursors. Trudy Geofizicheskogo instituta AN SSSR [Transactions of Geophys. Institute]. 1964, iss. 25 (152), pp. 162-180. (In Russian).

Kasahara K. Mekhanika zemletryasenii [Earthquake Mechanics]. Moscow, Mir Publ., 1985, 264 p. (In Russian). (English edition: Kasahara K. Earthquake Mechanics. Cambridge, University Press, 1981. 284 p.)

Masci F. Brief communication "On the recent reaffirmation of ULF magnetic earthquakes precursors". Nat. 
Hazards Earth Syst. Sci. 2011, vol. 11, pp. 2193-2198. DOI: 10.5194/nhess-11-2193-2011.

Moore G.M. Magnetic disturbances preceding the 1964 Alaska earthquake. Nature. 1964, vol. 203, no. 4944, pp. 508-509.

Nishida A. Geomagnitnyi diagnos magnitosfery [Geomagnetic Diagnosis of the Magnetosphere]. Moscow, Mir Publ., 1980, 299 p. (In Russian). (English edition: Nishida A. Geomagnetic Diagnosis of the Magnetosphere. New York, Heidelberg, Berlin, Springer-Verlag, 1978. 256 p.)

Parker E.N. Dinamicheskie protsessy v mezhplanetnoi srede [Dynamical Processes in Interplanetary Medium]. Moscow, Mir Publ., 1965, 302 p. (In Russian). (English edition: Parker E.N. Interplanetary Dynamical Processes. New York, Interscience Publ., 1963, 272 p.)

Russell C.T., Hoppe M.M. Upstream waves and particles. Space Sci. Rev. 1983, vol. 34, pp. 115-172.

Savin M.G., Smagin S.I. Application of MHD generators in geophysical research in the Far East. Vestnik DVO RAN [Vestnik (Bulletin) of the Far East Branch of the Russian Academy of Sciences]. 2004, no. 2, pp. 129-146. (In Russian).

Schekotov A.Yu., Fedorov E.I., Hobara Y., Hayakawa M ULF magnetic field depression as a possible precursor to the 2011/3.11 Japan earthquake. Telecommunications and Radio Engineering. 2012, vol. 71, iss. 18, pp. 1707-1718. DOI: 10.1615/TelecomRadEng.v71

Smirnov N.V., Dunin-Borkovsky I.V. Kurs teorii veroyatnostei i matematicheskoi statistiki [Course of probability theory and mathematical statistics]. Moscow, Nauka Publ., 1965,511 p. (In Russian).

Sobisevich L.E., Kanonidi K.K., Sobisevich A.L. Observations of ultra-low-frequency geomagnetic disturbances reflecting the processes of the preparation and development of tsunamigenic earthquakes. Doklady Earth Sci. 2010, vol. 435 , pp. 1627-1632. DOI: 10.1134/S1028334X10120160.

Tarasov N.T. Variation of seismicity of the Earth crust by electric impact. Doklady Rossiiskoi akademii nauk [Transactions (Doklady) of the Russian Academy of Sciences. Earth Science Sections]. 1997, vol. 353, no. 4, pp. 542 545]. (In Russian).

Tarasov N.T. On the influence of solar activity on the seismicity of the Earth. Triggernye effekty $v$ geosistemakh [Trigger effects in geosystems (Moscow, June 6-9, 2017): Proceedings of the IV All-Russian conference with international participation]. Moscow, GEOS Publ., 2017, pp. 356365. (In Russian).

Tarasov N.T., Tarasova N.V., Avagimov A.A., Zeigarnik V.A. The effect of high energy electromagnetic pulses on seismicity in Central Asia and Kazakhstan. Volcanology and Seismology. 2000, vol. 21, no. 4-5, pp. 627-639.

Tarasov N.T., Tarasova N.V., Avagimov A.A., Zeigarnik V.A. The effect of electromagnetic impacts on seismicity over the Bishkek geodynamic test ground. Geologiya $i$ geofizika [Geology and Geophysics]. 2001, no. 10, pp. 1641-1649. (In Russian).

Tobolzhina V.A. Volokonnaya struktura mezhplanetnogo magnitnogo polya [Fiber structure of the interplanetary magnetic field: Final qualifying work]. Tomsk, Tomsk State University, 2016, 80 p. (In Russian).

Velikhov E.P., Volkov Yu.M. Perspektiva razvitiya impul'snoi MGD-energetiki i eye primenenie $v$ geologii $i$ geofizike [Prospects for the development of pulsed MHD energy and its application in geology and geophysics: Preprint no. 3436/6, Institute of Atomic Energy]. Moscow, 1981, 28 p. (In Russian).

Zakrzhevskaya N.A., Sobolev G.A. On the seismicity effect of magnetic storms. Izvestiya. Physics of the Solid Earth. 2002, vol. 38, no. 4, pp. 249-261.

Zakrzhevskaya N.A., Sobolev G.A. The influence of the sudden-commencement magnetic storms on seismicity in dif- ferent regions. Vulkanologiya i seismologiya [Volcanology and Seismology]. 2004, no. 3, pp. 63-75. (In Russian).

Zotov O.D., Guglielmi A.V., Sobisevich A.L. On magnetic precursors of earthquakes. Izvestiya, Physics of the Solid Earth. 2013, vol. 49, no. 6, pp. 882-889. DOI: 10.1134/ S1069351313050145.

Zotov O.D., Lavrov I.P. On the relationship of the Earth's seismicity with the parameters of the interplanetary magnetic field. Sredneshyrotnye geofizicheskie observatorskie nabludeniya [Mid-latitude Geophysical Observatory observations: Proc. the Scientific-Practical Conference Dedicated to the 100th Anniversary of the Birth of Valeria Alekseevna Troitskaya and the 60th Anniversary of the Borok Geophysical Observatory (Borok, October 16-19, 2017)]. Yaroslavl, 2017, pp. 25-26. (In Russian).

URL: http://www.izmiran.ru/stp/polar/SSIMF/?ASCII (accessed January 7, 2017).

URL: http://www.isc.ac.uk (accessed February 26, 2012).

URL: http://neic.usgs.gov/neis/epic/epic_global.html (accessed May 4, 2017).

URL: http://www.ncedc.org (accessed January 7, 2016).

URL: http://www.data.scec.org (accessed January 7, 2016).

URL: http://www.gein.noa.gr (accessed March 25, 2010).

How to cite this article

Zotov O.D., Guglielmi A.V., Silina A.S. On possible relation of earthquakes with the sign change of the interplanetary magnetic field radial component. Solar-Terrestrial Physics. 2021. Vol. 7. Iss. 1. P. 59-66. DOI: 10.12737/stp-71202108. 